\title{
DE LAS REFORMAS CONSTITUCIONALES A LA REFORMA DEL ESTADO
}

\author{
The Constitutional Reforms To The Reform Of The State
}

Ismael PÉREZ SANTACRUZ*

Sumario:

I. Introducción II. Marco Constitucional en materia de política económica de 1917-1982 III. Política económica 1917-1982 IV. Reformas a la Constitución del ámbito económico 1982-2017- V. Conclusiones

Resumen: El presente artículo aborda el análisis de lo ocurrido a un siglo de promulgada la Constitución Política de los Estados Unidos Mexicanos de 5 de febrero de 1917, que se propuso responder a los ideales de la Revolución Mexicana de 1910. Se analizan las reformas constitucionales que, a partir de 1982 y hasta la fecha, con la llegada al gobierno federal de la denominada corriente tecnocrática, modificaron el contenido esencial del texto de 1917, dando paso a la conformación de un Estado de corte neoliberal por la vía pacífica y parlamentaria.

Palabras clave: Constitución Política de los Estados Unidos Mexicanos, reformas constitucionales, reforma neoliberal del estado.

Abstract: This article is aimed to analyze what happened a century after the promulgation of the 1917 Mexican Political Constitution, which intended to develop the ideals of the 1910 Mexican Revolution. It tackles the constitutional amendments which, since 1982 up to date, with the arrival of the so called technocrats to the Federal Government, modified the essentials of the 1917 Constitution, in order to orient the Mexican state towards a neoliberal regime, nevertheless by the means of a pacific and parliamentary way.

Key words: Mexican Constitution, Mexico Recent Constitutional Amendments, Neoliberal Reforms.

\section{Introducción}

El desarrollo económico de México —-después del triunfo de la Revolución Mexicana y la promulgación de la Constitución de 1917- se encamina, con inconsistencias e incongruencias,

\footnotetext{
* Profesor de la Facultad de Derecho, Ciencias Políticas y Criminología de la Universidad Autónoma de Tlaxcala.
} 
rumbo a la independencia económica y política de la nación y el mejoramiento de las condiciones de vida de los mexicanos, particularmente de los trabajadores del campo y de la ciudad.

Esos grandes objetivos guían, en lo general, la política de los diversos presidentes de la República durante 65 años: del gobierno de Venustiano Carranza —que comienza en 1917- al de José López Portillo - que finaliza en 1982-, con sus excepciones en uno u otro sentido: desde mandatarios progresistas y patriotas, hasta gobiernos al servicio del capital externo y la oligarquía mexicana.

A partir de 1924 y hasta 1982, se nacionalizan empresas fundamentales para la economía nacional y se constituyen empresas del Estado en ferrocarriles, petróleo, electricidad, hierro y acero, telefonía, banca, y otras. También se crean fideicomisos, organismos descentralizados e instituciones educativas, bancarias y de salud que dan sustento social al proyecto nacional. Con todas ellas se integra el sector estatal de la economía.

Durante un poco más de 34 años al amparo de las políticas neoliberales, se modifica la esencia del papel del Estado en la vida económica del país. Se utilizan argumentos diversos, y cada uno de los gobiernos de esta etapa tratan de justificar sus acciones, con los argumentos siguientes: el actual escenario internacional, caracterizado por la globalización y la interdependencia entre las naciones; el proteccionismo y paternalismo estatal, en estas nuevas condiciones, ya no responde a los desafíos que se le presentan; sólo una economía de mercado es capaz de enfrentar con éxito los retos que nos impone el mundo globalizado, para poder solucionar los múltiples problemas económicos y sociales que afectan al país y a la mayoría de la población.

Los resultados de esos sexenios no se corresponden con las promesas esgrimidas, en especial respecto de un posible crecimiento económico sostenido, acompañado de una menos injusta distribución del ingreso. Contrariamente a lo ofrecido, a lo largo de esos años la economía nacional se ha hecho cada vez más dependiente del capital externo, sobre todo estadounidense, con todas las consecuencias negativas que dicha situación produce.

Lo anterior se traduce en los siguientes aspectos negativos: la deuda del sector público federal - a pesar del pago de enormes sumas por concepto de intereses- continúa incrementándose y constituye un pesado lastre para la nación; la inversión extrajera, directa y de cartera, crece en forma permanente: la primera, apropiándose de empresas ya constituidas, estatales y de particulares, y la segunda, especulando con las necesidades públicas y privadas de capital; miles de micros, pequeñas y medianas empresas propiedad de nacionales han ido a la quiebra; hay menos recursos destinados a resolver problemas sociales; disminuye drásticamente el poder adquisitivo de los salarios, crece el desempleo, el subempleo y el empleo informal, así como la secuela de efectos sociales negativos que acompañan este tipo de problemas, como el incremento del narcotráfico, el narcomenudeo y la delincuencia en sus diversas facetas.

En contrasentido, los beneficiarios de la política neoliberal - el capital extranjero y la oligarquía mexicana vinculada a él- impulsan el mantenimiento y la profundización de las medidas que se plantean en el Consenso de Washington, denominado así por el economista inglés, John Williamson, que elaboró un decálogo para sintetizar los principales puntos de la política económica neoliberal1, diseñada por el Fondo Monetario Internacional, el Banco Mundial, la Organización para el Desarrollo y el Crecimiento Económicos y otros organismos semejantes, los que argumentan que esta es la única política que puede impulsar el desarrollo de los países dependientes, por lo que es necesario aplicar sus recetas económicas y sociales en forma orto-

\footnotetext{
1 Larrain, Max (1999), “El Consenso de Washington ¿Gobernador de gobiernos?”, agosto / 1999, propolco.tripod. com/4sem/washington.htm
} 
doxa y sin titubeos para que en un futuro — que no precisan y que cada vez se ve más lejanorinda los frutos que satisfagan a la población.

Los resultados obtenidos por los gobiernos neoliberales, demuestran que sus políticas no resuelven los problemas económicos y sociales que afectan al pueblo trabajador y al país en su conjunto; por el contrario, los agravan. Ante esa realidad, no es posible permanecer al margen del análisis crítico, del debate y la confrontación de puntos de vista y opiniones. Cada vez se hace más necesario precisar un nuevo camino, proponer una vía capaz de resolver los problemas que afectan a la nación mexicana y a la mayoría de sus habitantes.

Para cumplir con ese propósito es indispensable partir de la experiencia histórica, particularmente de lo logrado después del triunfo de la Revolución Mexicana, pero no para repetirla mecánicamente, sino para adecuarla a las nuevas circunstancias mundiales y a la actual situación del país.

\section{Marco constitucional en materia de política económica de 1917-1982}

La política económica aplicada por los gobiernos que se sucedieron de 1917 a 1982 no obedeció a un proyecto diseñado para responder a todos los problemas inmediatos, así como a los de mediano y largo plazos, sino, las más de las veces, se trató de soluciones parciales y unilaterales. A veces, las decisiones fueron, inclusive, contrarias a las aplicadas por gobiernos anteriores. Nunca se elabora un plan ni se ponen en práctica programas que señalen objetivos, tareas y mecanismos para consolidar la economía nacional.

Sin embargo y, a pesar de todas esas limitaciones, México logra desarrollarse en algunos aspectos importantes. La realidad y los principios contenidos en la Carta Magna que incluyen "las bases jurídicas para el desarrollo económico independiente de México”2 hacen avanzar al país con altibajos y venciendo numerosos obstáculos.

En los inicios de la etapa constructiva de la Revolución Mexicana se dan algunos pasos tímidos. Las prioridades del momento son otras y están encaminadas, fundamentalmente, a resolver problemas básicos, tanto por lo que se refiere a la consolidación política de los sectores que asumen el poder, como a la solución de los problemas más urgentes de las masas populares que participan en el movimiento armado.

A partir de la década de los treinta, las necesidades del país obligan al gobierno, impulsado y apoyado por la clase obrera, los campesinos y los sectores progresistas de otras clases sociales, a iniciar el proceso de participación activa del Estado en el proceso económico nacional, como productor directo de bienes y servicios indispensables para garantizar el desarrollo, con independencia del exterior y para satisfacer las demandas de las masas populares.

Todo ello apoyado en la Constitución de Querétaro, que "reivindicó para la nación los recursos naturales de su territorio, facultó al Estado para intervenir en el proceso económico, [y] creó los monopolios del Estado"3 y en las normas y mandatos legales derivados de sus postulados avanzados. La Constitución de 1917 sustituye el principio dominante en la de 1857 que afirma

\footnotetext{
${ }^{2}$ Lombardo Toledano, Vicente (en adelante VLT) (2009), "Carta a la juventud sobre la Revolución Mexicana. Su origen, desarrollo y perspectivas”, Obra histórico-cronológica, t. VI, vol. 3, México, CEFPSVLT, p. 58.

3 VLT (2014), "La Constitución y el desarrollo futuro de México", Obra histórico-cronológica, t. VI, vol. 21, México, CEFPSVLT, p. 59.
} 
que el individuo debe ser antes y más que la sociedad, por el que establece que la sociedad debe ser antes y más que el individuo ${ }^{4}$.

El saldo de la Revolución Mexicana hasta 1982, con sus etapas de ascenso y de avance, considerando su gran trascendencia histórica y también tomando en cuenta los obstáculos, las desviaciones, los errores, las traiciones y claudicaciones de quienes han estado al frente del poder público, es, en general, positivo. Gracias a ella, México deja de ser un país atrasado para transitar hacia un capitalismo de Estado que se caracteriza por suplir, en las áreas económicas más importantes, el capital extranjero y el capital mexicano que no tiene la capacidad ni el interés para asumir esa responsabilidad.

El capitalismo de Estado en México se apoya en la nacionalización de las riquezas naturales renovables y no renovables que están en manos del capital extranjero, lo que le permite convertirse en propietario de las principales fuentes de la producción económica y de los servicios. Esa política económica tiene como sustento un conjunto de principios nacionalistas que le permiten defender a México de la intervención de los monopolios del exterior, del capital financiero internacional y de los sectores de la burguesía mexicana que le sirven de instrumento.

De esa etapa, México aún conserva algunos rasgos importantes, sobre todo algunas empresas del Estado y diversas normas jurídicas constitucionales. Sin embargo, la intromisión económica del capital extranjero para hacer prevalecer sus intereses, así como los acontecimientos políticos internacionales de las últimas décadas del siglo $\mathrm{xx}$, que propician la aplicación de la política económica neoliberal en los últimos treinta años, lo han apartado totalmente de esa senda.

A pesar de todos los cambios negativos, la Constitución vigente mantiene algunos principios progresistas en materia económica. Unos provienen de la Constitución de 1857, mientras que otros, representan verdaderas innovaciones en el derecho constitucional, incluido por el Constituyente de Querétaro. De todos ellos se derivan las leyes reglamentarias y secundarias que, a pesar de lo acontecido, aún pueden ser útiles para impulsar medidas gubernamentales tendientes a garantizar el desarrollo económico con independencia.

Las principales normas relativas a la economía, contenidas en la Constitución promulgada el 5 de febrero de 1917, son las siguientes:

a) Artículo 27: La propiedad de las tierras y aguas comprendidas dentro de los límites del territorio nacional, corresponde originariamente a la nación.

La nación tiene el derecho de transmitir el dominio de ellas a los particulares, constituyendo la propiedad privada.

La nación tendrá en todo tiempo el derecho de imponer a la propiedad privada las modalidades que dicte el interés público; pero que ésta no podrá ser expropiada sino por causa de utilidad pública y mediante indemnización.

Corresponde a la nación el dominio directo sobre los bienes del subsuelo, y sobre las aguas de los mares territoriales en la extensión y términos fijados por el derecho internacional. Es un derecho exclusivo de los mexicanos adquirir el dominio de tierras y aguas, así como la explotación de minas y yacimientos.

Que la posibilidad de que los extranjeros puedan gozar de esa prerrogativa, requiere que convengan en considerarse nacionales respecto de esos bienes.

\footnotetext{
4 Molina Enríquez, Andrés (1985), “El espíritu de la Constitución de Querétaro”, en la antología, La Revolución Mexicana. Textos de su historia, t. IV, México, SEP / Instituto de Investigaciones Dr. José María Luis Mora, p. 137. 
Los extranjeros, en una franja de cien kilómetros en las fronteras y de cincuenta en las playas, por ningún motivo podrán adquirir el dominio de tierras y aguas ${ }^{5}$.

b) Artículo 28: Están prohibidos los estancos y los monopolios, así como todo acto que evite o tienda a evitar la libre concurrencia o impedir la competencia en la producción, la industria, el comercio o los servicios.

El gobierno federal, por medio de un solo banco, es el facultado para acuñar monedas y controlar la emisión de billetes ${ }^{6}$.

c) Artículo 31: Es obligación de los mexicanos, contribuir para los gastos públicos de la federación, el estado y el municipio en que residan, de la manera proporcional y equitativa que dispongan las leyes?

d) Artículo 131: Es facultad exclusiva de la federación gravar las mercancías que se importen o exporten ${ }^{8}$.

El más importante de esos principios es el relativo a la propiedad, que ya no es considerada como un derecho natural del individuo - como establecía la Constitución de 1857-, sino como propiedad de la nación, es decir, un atributo del Estado mexicano. La inclusión de esa norma representa un cambio sustancial respecto de la Constitución de 1857, significa que la Constitución de 1917 sustituye un elemento de la doctrina liberal que había orientado la política económica del Estado Mexicano anterior a la revolución de 1910, por un principio de carácter social. Otro aspecto sobresaliente es la marcada orientación de defensa de los intereses nacionales respecto de las agresiones del exterior, particularmente de los Estados Unidos.

También el derecho de la nación de expropiar, lo que permite el rescate de los recursos naturales que están en manos del capital extranjero. Los aspectos relativos a la educación, a la propiedad, al trabajo y a la religión, incorporados a la Constitución, logran que ésta sea considerada la más avanzada del mundo, cuando entra en vigor el 1 de mayo de 1917.

En la década de los años treinta, el Estado mexicano se enfrenta a diversos problemas que se resuelven con base en las orientaciones constitucionales avanzadas, lo que genera medidas de trascendencia para el desarrollo económico. Las nuevas condiciones que se crean al poner en práctica esas políticas convierten las empresas que estaban en poder del capital extranjero en empresas públicas.

Las adiciones positivas hechas al texto constitucional no sólo ayudan a orientar el desarrollo educativo, económico, social y cultural de la nación, sino que permiten que la Constitución sea considerada, durante largo tiempo, la más avanzada del mundo capitalista. Si antes de la llegada de los neoliberales al gobierno, "se comparan las Constituciones más progresistas con la de México, es fácil advertir que la nuestra no se limita a estructurar jurídica y políticamente a la nación, sino que encierra un conjunto de instituciones que forman verdaderos cuerpos de doctrina sobre cuestiones fundamentales"'.

5 Cámara de Diputados del Congreso de la Unión, Derechos del pueblo mexicano. México a través de sus constituciones, en doce tomos, t. IV, 4a. ed., México, LV Legislatura, pp. 542-543.

${ }^{6}$ Ibid.t. V, p. 79.

7 Ibid.p. 764.

8 Ibid. t. XII, p. 1152.

9 VLT (1992), "Proyecto para un nuevo capítulo de la Constitución Política de los Estados Unidos Mexicanos", en Escritos acerca de las constituciones de México, t. II, México, CEFPSVLT, p. 206. 


\section{Política económica 1917-1982}

La política económica, es el elemento esencial que pone en práctica los principios constitucionales avanzados para responder a las necesidades fundamentales para el desarrollo nacional con independencia del exterior.

Esa tarea no es capaz de asumirla el capital privado de México por su escaso desarrollo; pero, sobre todo, por la falta de visión y de interés de los empresarios. Por esa razón, es el Estado mexicano el que se ve obligado a emprender la tarea esencial de rescatar de manos del capital extranjero las empresas y áreas fundamentales de la economía y de convertirse en el productor directo de los bienes y servicios necesarios para el desarrollo de la industria nacional y para satisfacer las demandas esenciales de la población.

La orientación progresista de la Constitución y las acciones positivas de la burguesía nacional que detenta el poder, permiten que las ramas estratégicas de la economía nacional: petróleo, ferrocarriles y electricidad, entre otras, sean actividades reservadas al Estado Mexicano.

Ese proceso se desarrolla por diversas vías: por expropiación, como ocurre en el caso del petróleo; por creación de instituciones y empresas como sucede con la Comisión Federal de Electricidad y por compra de acciones como acontece con la Mexican Light and Power que se transforma en Compañía de Luz y Fuerza del Centro. En todos los casos, excepto en el caso de la banca, el Estado asume la propiedad y pone las empresas al servicio de la nación y no de los intereses privados.

La diferencia que existe entre esos dos términos es importante, porque no necesariamente todo lo que se expropia se nacionaliza. En el caso del petróleo y de la electricidad, se cumplieron los dos aspectos. La expropiación significa que grandes empresas propiedad del capital extranjero pasan a ser propiedad del Estado, y la nacionalización, que el petróleo y los demás hidrocarburos, así como la electricidad dejan de servir a los intereses del capital financiero internacional para servir a los de la nación mexicana. En el caso de la banca, no fue así, ésta se expropia, pero continúa sirviendo a los intereses particulares de un grupo, de un sector de la sociedad, debido al momento político en que se produce, previo al sexenio en el que se empieza a aplicar el proyecto neoliberal; se expropia, pero no se nacionaliza, continúa operando con los mismos criterios que cuando estaba en manos de capital privado ${ }^{10}$.

El momento fundamental del proceso de nacionalizaciones se inicia durante el gobierno del general Lázaro Cárdenas del Río (1934-1940), cuando se produce la expropiación petrolera el 18 de marzo de 1938. Esta acción, después de la independencia política, es la más importante en la historia del país porque está vinculada con la lucha por la independencia económica, y es posible realizarla por las décadas de lucha de los trabajadores petroleros, por la puesta en práctica de la estrategia diseñada y aplicada por Lombardo, en su carácter de secretario general de la Confederación de Trabajadores de México (CTM), y por la decisión patriótica del presidente Cárdenas de decretar la expropiación, que el propio general califica de "acto de esencial y profunda liberación económica"11.

A partir de la expropiación petrolera se transforma la industria del ramo para que Petróleos Mexicanos no sea solamente exportadora de petróleo crudo, por lo que se le incorporan la refinación y la petroquímica básica como facultades exclusivas del Estado Mexicano. La impor-

\footnotetext{
${ }^{10}$ Véase VLT (2008), “Expropiación, nacionalización y socialización”, Obra histórico-cronológica, t. VI, vol. 2, México, CEFPSVLT, pp. 109-113.

${ }^{11}$ CÁrdenas del Río, Lázaro (1974), "Expropiación de las compañías petroleras”, Materiales de cultura y divulgación política mexicana 11, México, PRI, p. 16.
} 
tancia de Pemex para el desarrollo del país no está en duda, ni por el porcentaje de su aporte al producto interno bruto, ni por el ingreso de divisas por sus exportaciones, mucho menos por su contribución a las finanzas públicas, ello a pesar de que, de 1938 a la fecha, la conducción de esta empresa no siempre fue la más adecuada. A lo largo de su historia se producen casos de corrupción, de desvío de recursos, de traición a los objetivos nacionales, de ineficiencia y una larga lista de actitudes contrarias al desarrollo de la paraestatal.

En el caso de la electricidad, en la exposición de motivos de la iniciativa presidencial para reformar la Constitución —en 1960- el presidente de la República, Adolfo López Mateos (19581964) hace énfasis en el papel de las empresas estatales al señalar que: México ha sostenido tradicionalmente la tesis de que los recursos naturales y las fuentes de energía básica, han de estar al servicio de la colectividad y de la elevación de los niveles de vida del pueblo mexicano ${ }^{12}$.

A partir de esta concepción y de consideraciones políticas y económicas importantes para la nación y el desarrollo del país, se establece que la generación, conducción, transformación, distribución y abastecimiento de energía eléctrica que tenga por objeto la prestación de un servicio público, será una facultad exclusiva del Estado y que en esa materia no se otorgarán concesiones a los particulares.

El proceso de nacionalización de la economía se produce a lo largo de casi cinco décadas. Ejemplos significativos de las últimas nacionalizaciones de esta etapa son: la realizada en 1972 por el presidente Luis Echeverría Álvarez (1970-1976), al adquirir la mayoría de las acciones de Teléfonos de México, que se convierte en una empresa de participación estatal mayoritaria; así como la expedición del decreto que anuncia en su último informe de gobierno el presidente, José López Portillo (1976-1982), que expropia las instituciones de crédito privadas y establece el control generalizado de cambios $^{13}$.

De 1936 a 1982, la constante es el proceso de nacionalización de las ramas y áreas más importantes de la economía nacional al amparo de la Constitución y las leyes, y una intervención cada vez mayor del Estado como propietario de un importante número de organismos y empresas con los que se constituye el sector estatal de la economía, que le permite al gobierno resistir múltiples presiones del exterior, sobre todo para cambiar los aspectos más positivos de su política internacional, defender los recursos naturales no renovables como el petróleo y para avanzar en muchos de los aspectos de la vida nacional. La fortaleza económica que significa ser propietario de las principales empresas del país, se convierte en fortaleza para resistir, en la actividad gubernamental, las presiones del capital financiero internacional y de la oligarquía local.

Durante seis décadas, unas veces con decisión patriótica, algunas con titubeos y las menos con posiciones contrarias al camino abierto por la Revolución Mexicana, los gobiernos aplican una política económica y social, y crean las instituciones que consideran más convenientes para el desarrollo del país.

El presidente Plutarco Elías Calles (1924-1928) crea el banco central de la nación, el Banco de México, con las atribuciones de emitir billetes, regular la circulación monetaria, la política cambiaria y las tasas de interés, descontar documentos mercantiles y encargarse del servicio de tesorería del gobierno federal; crea la Dirección de Pensiones Civiles en beneficio de los trabajadores del Estado; construye las primeras carreteras y obras de irrigación, y da los primeros

\footnotetext{
${ }^{12}$ Cámara de Diputados del Congreso de la Unión, Derechos del pueblo... op. cit. nota 5, t. iv, p. 719.

${ }^{13}$ De Anda Gutiérrez, Cuauhtémoc (1982), La nacionalización de la banca, México, IPN, 1982. pp. 111-124.
} 
pasos en dirección de la producción económica y de la ampliación de los servicios como tareas naturales del poder público.

Los gobiernos posteriores imponen normas para la agricultura; fomentan obras de riego; crean el crédito agrícola y el seguro para los riesgos de la agricultura; crean el Instituto Mexicano del Seguro Social y el Instituto de Seguridad Social al Servicio de los Trabajadores del Estado; dictan medidas para encauzar el crédito privado hacia las actividades agrícolas e industriales; nacionalizan empresas fundamentales para el desarrollo del país, las telecomunicaciones, parte de la aviación civil, la telefonía, la industria dedicada a producir carros de ferrocarril, la de fertilizantes para la agricultura, los ingenios azucareros, fábricas textiles y productoras de papel, e inician la fabricación de bienes de capital. Además, dictan normas para regular el comercio interior y exterior, crean un banco especial para este último aspecto y toman un conjunto de medidas de carácter progresivo en otras áreas.

La política de nacionalizaciones genera que al finalizar el año de 1982, después de la expropiación bancaria, se encuentren en poder del Estado, 1155 empresas e instituciones: unas de carácter estratégico, señaladas en el artículo 28 constitucional; otras prioritarias para impulsar el desarrollo económico y el bienestar popular; algunas de menor importancia, y otras que carecían de relevancia para las tareas fundamentales del Estado ${ }^{14}$.

A pesar de la importancia del proceso de nacionalizaciones y de la fortaleza económica del Estado, Lombardo considera indispensable señalar que aun cuando el patrimonio nacional crece, esa política también tiene su lado negativo, porque la explotación de las riquezas naturales y el empleo de los recursos financieros del país, a pesar de los aspectos positivos que tiene para la nación y el pueblo, también se orienta para beneficiar a una minoría por medio de exenciones de carácter fiscal, y precios de materias primas de origen público por debajo de su costo de producción. Esto último favorece a las grandes empresas nacionales y extranjeras ${ }^{15}$.

\section{Reformas a la constitución del ámbito económico 1982-2017}

A partir de 1982, inicia el proceso para implantar la política neoliberal, diametralmente opuesta a los principios positivos contenidos en la Constitución de México. Las primeras medidas modifican el marco constitucional con la finalidad de: a) desincorporar empresas públicas por medio de la venta de la mayoría de ellas al capital privado, particularmente extranjero; la entrega de otras a las entidades federativas; la fusión de otras más y la extinción de las demás; b) la reducción de los recursos presupuestales para la inversión productiva y la atención de los problemas sociales, la supresión de los subsidios al consumo popular y de los precios de garantía a los productos del campo, y la imposición de topes a los incrementos salariales.

La implantación del programa neoliberal inicia con dos medidas de carácter legislativo. El 3 de diciembre de 1982, apenas dos días después de haber tomado posesión de la Presidencia del país, Miguel de la Madrid envía simultáneamente a cada una de las cámaras del Congreso de la Unión, sendas iniciativas para modificar la Constitución. Dichos cambios —aparentemente desvinculados entre sí- están orientados a satisfacer los mismos objetivos.

El Presidente envía a los diputados la iniciativa en materia económica que propone se adicionen, reformen o modifiquen los artículos $16,25,26,27,28$ y 73 constitucionales. Incluye

\footnotetext{
14 Secretaría de Hacienda y Crédito Público (1991), El proceso de enajenación de entidades paraestatales, México, SHCP, p. 13.

${ }^{15}$ VLT (2011), “Moscú o Pekín? La vía mexicana hacia el socialismo”, Obra histórico-cronológica, t. VI, vol. 11, México, CEFPSVLT, pp. 115-116.
} 
argumentos contra la intervención del Estado en la economía, que solamente habían utilizado los partidos y fuerzas de la derecha tradicional. Después de acalorados debates, la Cámara la aprueba sin enmiendas esenciales, y la turna al Senado que ratifica lo aprobado. Las modificaciones incorporan el concepto rectoría del Estado que lo limita a establecer las reglas de la participación económica de los particulares; incluye el apoyo a los empresarios, sin hacer distingos entre nacionales y extranjeros, y otras medidas similares ${ }^{16}$. Al Senado de la República, el Mandatario envía la iniciativa que corresponde a la renovación moral de la sociedad, en la que propone reformas y adiciones al Título Cuarto de la Constitución, así como a sus artículos 22, $72,74,76,94,97,127$ y $134^{17}$

La propuesta para modificar el artículo 134 tiene como propósito establecer reglas claras para que el Estado mexicano al comprar, vender o realizar cualquier acto de naturaleza semejante lo haga por medio de licitaciones públicas. Para comprender este aspecto, es indispensable señalar que en derecho constitucional rige el principio de que lo que no está expresamente facultado no lo puede realizar la autoridad, porque "los poderes federales no son sino representantes con facultades establecidas y especificadas; y cualquier ejercicio de facultades no conferidas es un exceso en la comisión e implica un acto nulo"18, y antes de esta reforma no había norma constitucional que autorizara al gobierno a vender las empresas estatales, porque el artículo 90 que establece las formas para que el Estado cree, adquiera, y administre empresas, no le faculta para su venta.

A partir de las modificaciones constitucionales, inicia el procedimiento llamado eufemísticamente, desincorporación de empresas públicas. Al concluir el sexenio se producen los siguientes resultados: al inicio, el gobierno federal participa en 45 ramas y al final solamente lo hace en 23; inicia con 1155 instituciones y empresas, y finaliza con 412. De las 705 desincorporadas, 219 son vendidas (30\%)19. El gobierno federal informa que sólo se habían desincorporado empresas que no eran estratégicas ni prioritarias para el desarrollo nacional, que $18 \%$ de las empresas vendidas tenían como nuevo dueño al sector social, y que en más de 90\% de los casos, los compradores habían sido inversionistas nacionales ${ }^{20}$.

El presidente, Miguel de la Madrid, afirma que se podría iniciar una mejor etapa de la historia porque se estaban sentando bases sólidas, "a partir de una readecuación presupuestal y disciplina estricta del gasto público" ${ }^{21}$. Esa orientación económica y social se intensifica a partir de 1988, durante el sexenio de Carlos Salinas (1988-1994), cuando por la venta de empresas estatales se obtienen casi 65 mil millones de nuevos pesos (20 mil millones de dólares) ${ }^{22}$; se pretende convertir en política de Estado durante el mandato de Ernesto Zedillo (1994-200o), cuyas diez tesis socioeconómicas fundamentales las formula durante su campaña presidencial ${ }^{23}$, pero no puede llevarlas a la práctica debido al llamado error de diciembre, que devaluó el peso en su

\footnotetext{
${ }^{16}$ Cámara de Diputados del Congreso de la Unión, Derechos del pueblo... op. cit., t. iii, pp. 252-295.

${ }^{17}$ Ibíd., pp. 1106-1119.

18 Tena Ramírez, Felipe (1984), Derecho constitucional mexicano, México, Porrúa, p. 115.

19 Secretaría de Hacienda y Crédito Público (1991), La venta de empresas del sector público. Fundamentos, procedimientos y resultados 1983-1988, México, SHCP, p. 60.

${ }^{20}$ Ibíd., p. 72.

${ }^{21}$ Gutiérrez, Elvia y Víctor Felipe Piz (1995), "La política económica en México: 25 años sin rumbo y a la deriva”, El Financiero, México, D. F. 22 de octubre de 1995, p 10.

22 Rogozinski, Jacques (1993), La privatización de empresas estatales, México, FCE, p. 204.

${ }^{23}$ Zedillo, Ernesto (1994), Propuestas y compromisos, México, Limusa, pp.61-82.
} 
primer mes de gobierno, elevó de nuevo la inflación y desplomó el producto interno bruto (PIB) en $1995^{24}$.

La política neoliberal continúa aplicándose durante el sexenio de Vicente Fox (2000-2006), que se promociona como el gobierno del cambio; sin embargo, nada cambió, los resultados fueron igual o peor de negativos que los tres anteriores: la economía no crece lo necesario, la deuda bruta total del sector público federal sigue aumentando, al igual que la inversión extranjera directa (IED), que es mayor que en los anteriores gobiernos neoliberales ${ }^{25}$. En el ámbito social no logra cumplir con sus promesas de campaña. Felipe Calderón (2006-2012), que cuando asume el cargo se autonombra el Presidente del empleo, fracasa al igual que su antecesor, pero además, deja decenas de miles de muertos por su combate a la delincuencia. En su sexenio promovió una iniciativa de ley preferente para reformar la Ley Federal del Trabajo, con los objetivos de flexibilizar el mercado laboral, y legalizar el outsourcing — subcontratación o tercerización-, así como otras normas que anulan diversas conquistas sindicales. Extinguió, mediante un decreto, la Compañía de Luz y Fuerza del Centro ${ }^{26}$, medida que dejó sin empleo a 44 mil trabajadores. En su administración, marcada por los gastos excesivos y la opacidad en el manejo de los recursos, tampoco estuvo ausente la corrupción: la Auditoría Superior de la Federación, en la Cuenta Pública de 2011, informó de "pagos improcedentes por 248.9 millones de pesos [...] así como de otras erogaciones presumiblemente ilegales por 150.3 millones de pesos" 27 .

En conjunto, de 1982 a 2012, los presidentes de la República enviaron 107 iniciativas de reformas constitucionales para realizar cambios a 339 artículos de la Carta Magna —algunos se modifican varias veces-, y también promueven cambios jurídicos a la mayoría de las leyes ${ }^{28}$. La última reforma relacionada con la economía nacional se realiza durante el actual sexenio, el 20 de diciembre de 2013, cuando se reforman y adicionan los artículos 25, 27 y 28 constitucionales, que, bajo la denominación de reforma energética, forma parte de un conjunto de cambios esenciales conocidos como reformas estructurales. Esta reforma permite y propicia la participación, mediante contratos con particulares nacionales y extranjeros, en la exploración y extracción de petróleo, así como en el servicio público de transmisión y distribución de energía eléctrica. Hasta el momento, durante el actual sexenio, se han enviado y aprobado 26 iniciativas que incluyen cambios a 151 artículos constitucionales ${ }^{29}$.

Las acciones emprendidas durante treinta y cuatro años por los gobiernos neoliberales (19822017) modifican en sentido negativo diversos artículos constitucionales y un gran número de leyes secundarias, con la finalidad de vender la mayor parte de las entidades paraestatales que forman parte de la administración pública federal, y de permitir la presencia del capital extranjero en empresas que antes estaban reservadas al Estado - algunas de áreas estratégicas de la economía nacional- o a sectores específicos del país, como las cooperativas.

Cada uno de los gobernantes neoliberales ofrece solucionar los grandes problemas nacionales y populares para tratar de justificas esas medidas lesivas al patrimonio público. Pero a pesar de sus reiteradas promesas de campaña, ninguno logra resolver los problemas de la economía

\footnotetext{
24 "Registra el PIB per cápita la mayor caída en tres sexenios”, El Universal, México, D. F., 20 de noviembre de 1996.

25 BANCO DE MÉxico, Informe anual, ejemplares de 2001-2006.

${ }^{26}$ Calderón Hinojosa, Felipe de Jesús (2009), "Decreto por el que se extingue el organismo descentralizado Luz y Fuerza del Centro", Diario Oficial de la Federación, 11 de octubre de 2009, [en línea] disponible en: http://www. dof.gob.mx/nota_detalle.php?codigo $=5114004 \&$ fecha $=11 / 10 / 2009$

27 "Estela de Luz: corrupción emblemática", La Jornada, México, D. F., 21 de febrero de 2013.

${ }^{28}$ Véase "Reformas constitucionales por periodo presidencial", Cámara de Diputados del Congreso de la Unión, [en línea] disponible en: http://www.diputados.gob.mx/LeyesBiblio/ref/cpeum_per.htm

${ }^{29}$ Idem.
}

CIENCIA JuRÍDICA. Departamento de Derecho. División de Derecho, Política y Gobierno, Universidad de Guanajuato - Año 7, No. 14, 2018 
nacional y mejorar las condiciones de vida del pueblo. Sólo algunos aspectos tienen solución transitoria y fugaz, mientras que otros carecen de trascendencia por no estar acompañados de otras soluciones favorables.

Mientras los gobiernos anteriores a 1983 acrecientan el patrimonio nacional, los seis gobiernos neoliberales reducen significativamente el número de entidades del sector público, que pasa de 1155 en 1982 a 201 en 2016 -cuatro están en proceso de desincorporación y 16 son empresas productivas subsidiarias de dos empresas productivas del estado-, por lo que en realidad se han reducido 181. Debido a la desincorporación de entidades del sector paraestatal, este se reduce $84.3 \%$. En el caso de las empresas de participación estatal mayoritaria que forman parte de este sector, el porcentaje de la disminución es mayor, ya que de 744 empresas existentes en 1982 pasa a sólo 47 en 2016 , se reduce $93.7 \%^{30}$.

Gran parte de los recursos obtenidos por la venta de esas empresas han servido para pagar los intereses de la deuda del sector público federal, y la deuda, a pesar de ello, ha seguido creciendo en términos absolutos y relativos. La deuda interna bruta del sector público federal (SPF), al finalizar 2016, era de 6 billones 182251 millones de pesos, y la externa de 180986 millones de dólares; en total, la deuda bruta del SPF, en pesos, era de 9 billones 934344 millones, mientras que su equivalente en dólares fue de 479193 milllones, y representaba 50.9 del producto interno bruto de ese año ${ }^{31}$.

\section{Conclusiones}

Producto de las políticas de los seis últimos gobiernos federales, la economía no crece lo necesario, el endeudamiento se acrecienta, aumenta la dependencia respecto del exterior, particularmente de Estados Unidos de Norteamérica, y los problemas sociales se agudizan cada día más. A pesar de estos resultados negativos, se insiste en las medidas que generan estos resultados adversos.

Para la sociedad en su conjunto, el éxito o el fracaso de las políticas económicas se refleja en las consecuencias, buenas o malas, para la población, sobre todo para los trabajadores y sus familias que han visto incrementarse el desempleo y el trabajo informal, con su consecuencia inevitable: el aumento de la pobreza que llegó en 2014 a 55.3 millones de personas (46.2\% de la población), y de la miseria que llegó a 11.4 millones (9.5\% de la población) ${ }^{32}$ que no pueden ser considerados positivos, aunque transitoriamente algunos de los indicadores macroeconómicos lo sean.

Además de las reformas constitucionales en el ámbito económico, se han realizado una buena cantidad en el ámbito electoral y para actualizar las funciones de los poderes públicos de la federación, las relaciones entre ellos, así como con los estados y municipios, y también se han actualizado las funciones de estos últimos.

Las innumerables reformas constitucionales, a la parte orgánica de la Constitución, han abarcado las funciones económicas y políticas del Estado mexicano. Debido a este hecho es posible

\footnotetext{
${ }^{30}$ Secretaría de Hacienda y Crédito Público (2016), "Relación de entidades paraestatales de la administración pública federal", DOF, 15 de agosto de 2016.

${ }^{31}$ Secretaría de Hacienda y Crédito Público, Informes sobre la Situación Económica, las Finanzas Públicas y la Deuda Pública, [en línea] disponible en: http://finanzaspublicas.hacienda.gob.mx/es/Finanzas_Publicas/ Informes_al_Congreso_dela_Union

32 [En línea] disponible en: http://www.coneval.org.mx/SalaPrensa/Documents/Comunicadooo5_Medicion_pobreza_2014.pdf
} 
dar una respuesta positiva a la pregunta de si ¿Ha concluido la reforma del Estado?, o debemos esperar otras modificaciones en alguno de los ámbitos mencionados.

En todo caso, parece que lo más conveniente sería realizar una reforma integral a la Constitución, pero, en las actuales condiciones y escenario nacional e internacional, además habría que valorar la reciente experiencia de la elaboración de la Constitución de la Ciudad de México, ¿valdría la pena convocar a una asamblea constituyente?, ¿esa sería la solución, o agravaría aún más la situación del país?

\section{Bibliografía}

Calderón Hinojosa, Felipe de Jesús (2009), "Decreto por el que se extingue el organismo descentralizado Luz y Fuerza del Centro", Diario Oficial de la Federación, 11 de octubre de 2009, en http://www.dof.gob.mx/nota_detalle.php?codigo=5114004\&fecha=11/10/2009

CÁrdenas del Río, Lázaro (1974), "Expropiación de las compañías petroleras”, Materiales de cultura y divulgación política mexicana 11, México, PRI, p. 16.

DE Anda Gutiérrez, Cuauhtémoc (1982), La nacionalización de la banca, México, IPN. pp. 111-124.

Editorial (2013), “Estela de Luz: corrupción emblemática”, La Jornada, México, D. F., 21 de febrero de 2013.

Gutiérrez Elvia y Víctor Felipe Piz (1995), “La política económica en México: 25 años sin rumbo y a la deriva”, El Financiero, México, D. F. 22 de octubre de 1995, p 10.

Larrain, Max (1999), “El Consenso de Washington ¿Gobernador de gobiernos?”, agosto / 1999, propolco.tripod.com/4sem/washington.htm

Lombardo Toledano, Vicente (2009), "Carta a la juventud sobre la Revolución Mexicana. Su origen, desarrollo y perspectivas”, Obra histórico-cronológica, t. VI, vol. 3, México, CEFPSVLT, p. 58.

(2014), "La Constitución y el desarrollo futuro de México", Obra histórico-cronológica, t. VI, vol. 21, México, CEFPSVLT, p. 59.

(1992), "Proyecto para un nuevo capítulo de la Constitución Política de los Estados Unidos Mexicanos", en Escritos acerca de las constituciones de México, t. II, México, CEFPSVLT, p. 206.

(2008), “Expropiación, nacionalización y socialización”, Obra histórico-cronológica, t. VI, vol. 2, México, CEFPSVLT, pp. 109-113.

(2011), “¿Moscú o Pekín? La vía mexicana hacia el socialismo”, Obra histórico-cronológica, t. VI, vol. 11, México, CEFPSVLT, pp. 115-116.

Migueles, Rubén (1996), “Registra el PIB per cápita la mayor caída en tres sexenios”, El Universal, México, D. F., 20 de noviembre de 1996. 
Molina EnríQuez, Andrés (1985), "El espíritu de la Constitución de Querétaro”, en la antología, La Revolución Mexicana. Textos de su historia, t. IV, México, SEP / Instituto de Investigaciones Dr. José María Luis Mora, p. 137.

Rogozinski, Jacques (1993), La privatización de empresas estatales, México, FCE, p. 204.

Tena Ramírez, Felipe (1984), Derecho constitucional mexicano, México, Porrúa, p. 115.

Zedillo, Ernesto (1994), Propuestas y compromisos, México, Limusa, pp.61-82.

Banco de México, Informe anual, ejemplares de 2001-2006.

Cámara de Diputados del Congreso de la Unión, Derechos del pueblo mexicano. México a través de sus constituciones, en doce tomos, t. IV, 4a. ed. México, LV Legislatura, pp. 542-543.

Secretaría de Hacienda y Crédito Público, El proceso de enajenación de entidades paraestatales, México, SHCP, 1991, p. 13.

Secretaría de Hacienda y Crédito Público, La venta de empresas del sector público. Fundamentos, procedimientos y resultados 1983-1988, México, SHCP, 1991, p. 60.

Secretaría de Hacienda y Crédito Público, "Relación de entidades paraestatales de la administración pública federal”, DOF, 15 de agosto de 2016.

Secretaría de Hacienda y Crédito Público, Informes sobre la Situación Económica, las Finanzas Públicas y la Deuda Pública, [en línea] disponible en: http://finanzaspublicas.hacienda. gob.mx/es/Finanzas_Publicas/Informes_al_Congreso_dela_Union

"Reformas constitucionales por periodo presidencial", Cámara de Diputados del Congreso de la Unión, [en línea] disponible en: http://www.diputados.gob.mx/LeyesBiblio/ref/ cpeum_per.htm

[En línea] disponible en: http://www.coneval.org.mx/SalaPrensa/Documents/Comunicadooo5_Medicion_pobreza_2014.pdf 
